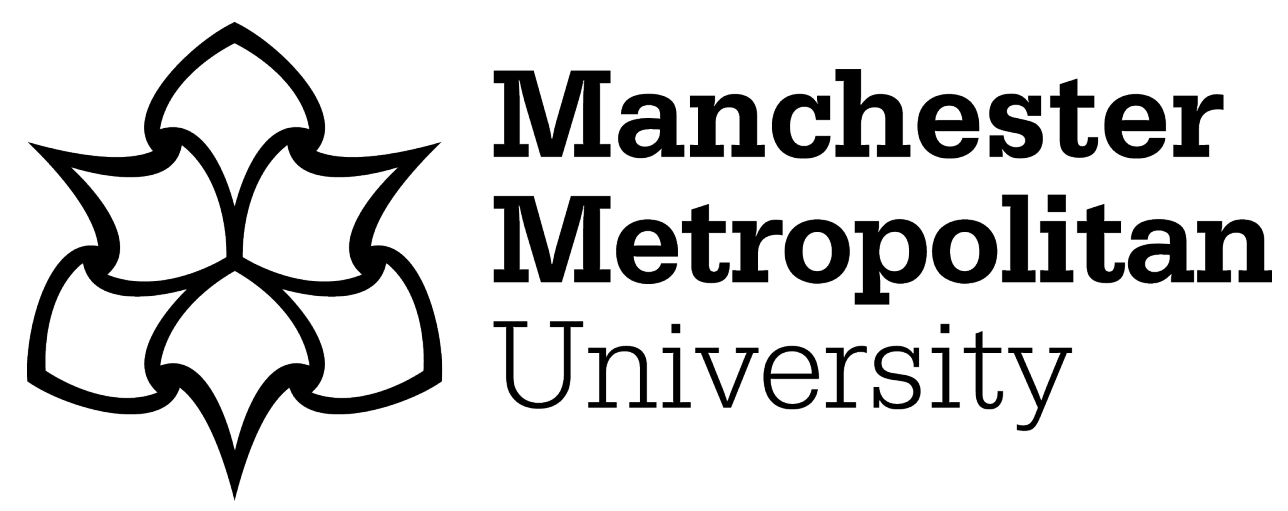

Oldfield, Jeremy, Robinson, R and Bond, C (2017) A UK and Ireland survey of Educational Psychologists' intervention practices for students with Autism Spectrum Disorder. Educational Psychology in Practice, 34 (1). pp. 58-72. ISSN 0266-7363

Downloaded from: https://e-space.mmu.ac.uk/619575/

Version: Accepted Version

Publisher: Taylor \& Francis (Routledge)

DOI: https://doi.org/10.1080/02667363.2017.1391066

Please cite the published version 


\section{A UK and Ireland survey of Educational Psychologists' intervention practices for students with Autism Spectrum Disorder.}

Lee Robinson, Caroline Bond,

Manchester Institute of Education, University of Manchester, Manchester, UK

Jeremy Oldfield

Department of Psychology, Manchester Metropolitan University, UK

Correspondence concerning this article should be addressed to Mr Lee Robinson, c/o Dr

Caroline Bond, Manchester Institute of Education, University of Manchester, Oxford Road,

Manchester, M13 9PL. E-mail: lee.robinson-3@postgrad.manchester.ac.uk 


\title{
A UK and Ireland survey of Educational Psychologists' intervention practices for students with Autism Spectrum Disorder.
}

\begin{abstract}
Although evidence-based interventions (EBIs) for Autism Spectrum Disorder (ASD) have been identified in recent systematic literature reviews, the extent to which the practice of educational psychologists (EPs) in the UK and Ireland is informed by these is unknown. This study presents the results of a questionnaire which surveyed 146 EP practitioners in the UK and Ireland about their use of 31 EBIs for ASD. This survey also explored the factors which influence EP practitioners' decision-making when planning interventions for students with ASD. Out of the 31 EBIs, EP Practitioners were most often involved with implementing visual supports, social stories, reinforcement, antecedent-based interventions, prompting, and social skills training. The most salient factors which influenced EP Practitioners' decision-making when planning interventions for students with ASD included the student's individual needs and factors related to the school context. Implications for EP practice are discussed in addition to the limitations of this study.
\end{abstract}

Keywords: autism, evidence-based interventions, educational psychologists

\section{Introduction}

Young people with Autistim Spectrum Disorders (ASD) experience impairments in social communication and interaction in addition to experiencing repetitive and stereotyped behaviours and interests (American Psychiatric Association, 2013). In the UK, ASD occurs in 1\% of children (National Institute for Health and Clinical Excellence, 2011). In England, ASD is one of the most common primary needs among students with special educational needs (SEN) (Department for Education [DfE], 2016) and 71\% of pupils with a diagnosis of ASD attend a mainstream school (DfE, 2014).

As the needs of students with ASD often cover a number of SEN categories, such as Social, Emotional and Mental Health; Cognition and Learning; and Sensory Needs, (DfE, 2014), it is important that educational psychologists (EPs) are familiar with a range of approaches, strategies and interventions which will support students with ASD to achieve 
personalised outcomes whether this is part of statutory advice or supporting schools through ongoing casework with students. Although there is evidence of which interventions are deemed to have the best empirical support (Bond, Symes, Hebron, Humphrey, \& Morewood, 2016; Wong et al., 2013), there is currently an absence of information about which ASD interventions are being implemented in the UK and Ireland. Research into the practice of EPs in the UK in relation to ASD has focused exclusively on their contributions to assessment and diagnosis (Waite \& Woods, 1999). As a result, there is a paucity of empirical research in the UK and Ireland investigating EPs' use of interventions for ASD.

\section{Using ASD interventions in schools}

Since 2009, researchers have endeavoured to identify evidence-based interventions (EBIs) for ASD with the most recent systematic literature reviews identifying 31 focused EBIs between them (Bond, Symes, Hebron, Humphrey, \& Morewood, 2016; Wong et al., 2013). These are discrete rather than comprehensive interventions. Research into the use of school-based interventions for ASD has emanated from the US and is driven by the evidence-based practice (EBP) agenda. In the US, school psychologists (SPs) are required by law to recommend and implement only those interventions which are deemed to be evidence-based (IDEA, 2004). A recent US survey of SPs (Sansosti \& Sansosti, 2013) found that SPs used many of the EBIs recommended by the National Standards Project (National Autism Center, 2009). Out of 13 established or emerging interventions, SPs were highly likely to recommend behavioural interventions and visual supports yet only somewhat likely to recommend counselling, self-management and computer-assisted instruction. It was also found that there was a high degree of unfamiliarity with some interventions among SPs such as child-directed teaching interactions, story-based approaches, and social skills strategies.

In the UK and Ireland, EBP is less of a driver in education and there is no legal requirement for EPs to use EBIs (Burnham, 2012; Goldacre, 2013). As a result it is likely that 
there are factors other than the evidence base which influence EPs' decisions when recommending/suggesting interventions. In the UK, it has been suggested that EPs regard the utility and social value of their practice as more important than an established evidence base (Burnham, 2012). Whilst EPs believed there are benefits to their professional practice being grounded in scientific enquiry, Burnham (2012) found that EPs are pragmatic in the development of bespoke solutions in naturalistic contexts using the resources that are at hand as opposed to relying solely on evidence-based interventions.

\section{Considerations when using best available evidence}

While Sansosti and Sansosti (2013) explored psychologists' use of EBIs, they did not explore which factors were taken into consideration by psychologists when they were making decisions about implementing interventions. Several models of EBP have been proposed. These models have three elements in common which influence decision-making regarding intervention implementation: best available evidence, client characteristics and availability of resources (Sackett, Rosenberg, Gray, Haynes, \& Richardson, 1996; Spring et al., 2008). These models make it clear that best available evidence is only one element of an EBP approach to intervention. Consideration of factors that affect implementation such as the client's characteristics, values and preferences in addition to availability of resources in the context are also important.

Students with ASD are a heterogeneous group and as such EPs will work with students with ASD who have disparate needs (Dingfelder \& Mandell, 2011). EPs must consider how an intervention can meet the needs of individual students with ASD, their family and school (Miller \& Frederickson, 2006). Additionally, the implementation of an intervention which is evidence-based is a moot point unless there is a trained practitioner available to deliver it (Spring \& Hitchcock, 2010) and deliver it with fidelity (Durlak \& 
DuPre, 2008). Currently, the extent to which EPs consider these factors when implementing interventions for students with ASD is unknown.

\section{Rationale}

There is a lack of UK research into EPs' intervention practices for students with ASD.

Although EBIs for ASD have been identified, it is not known to what extent they are being used by EPs in the UK and Ireland. There is also a paucity of research exploring the factors that influence EP practitioners' decision-making when selecting interventions for students with ASD. This study expands upon the approach of Sansosti and Sansosti (2013) through the use of an updated and larger range of EBIs and an exploration of factors, other than the evidence-base for an intervention, which may influence EPs' decision-making in relation to interventions for students with ASD.

\section{Research Questions}

(1) To what extent are EPs in the UK and Ireland using focused EBIs for students with ASD?

(2) Which factors influence EPs' decision-making in relation to ASD interventions?

\section{Method}

\section{Design}

This study adopted an exploratory survey design. Data were collected for this study using a questionnaire which was distributed to EPs in the UK and Ireland. The questionnaire was hosted online using Key Survey between 07.12.16 and 31.01.17.

\section{Participants and Sampling}

A non-probability, purposive sampling procedure was used in this study to directly target the population of EPs in the UK and Ireland. Participants were recruited through three avenues; 
an invitation to participate through the JISCMail forum, EPNET - an email forum supporting the exchange of ideas within the EP profession; direct email to the National Educational Psychology Service (NEPS) in Ireland; and emails to programme leaders of the Educational and Child Psychology Doctorate programmes in the UK, training providers for EPs. In each case, participants were self-selecting. Participants were required to be practicing EPs, Trainee Educational Psychologists (TEPs), or Assistant EPs with or without an ASD specialism.

\section{Materials}

A questionnaire was selected as an appropriate data collection method as the researchers aimed to collect a large amount of data from a large number of people (Cohen, Manion, \& Morrison, 2013). The structure of the questionnaire was based on previous literature (Sansosti $\&$ Sansosti, 2013) and consisted of two sections. The first section contained 13 items relating to demographic information such as gender, professional role, number of years working as a qualified EP, specialisms and type, size and location of educational psychology service (EPS).

The second section of the questionnaire asked participants to estimate the proportion of ASD intervention activity they were engaged in during the past year and also included 12 items about intervention practices. A list of 31 EBIs synthesised from recent systematic literature reviews (Bond, Symes, Hebron, Humphrey, \& Morewood, 2016; Wong et al., 2013) was presented and EPs were asked to identify the extent to which they have been involved with implementing each EBI. For all ratings, participants used the following scale: $1=$ never, $2=$ rarely, $3=$ sometimes, $4=$ often, $5=$ always.

The second section also contained questions which asked participants about factors influencing their decision-making when choosing an intervention (for example, individual 
child's needs, school context and evidence base). This was followed up with a qualitative question asking EPs to explain how these factors have influenced their decision-making.

The questionnaire was piloted during June 2016 with 5 TEPs and 5 EPs for; clarity of questions, appropriateness of response format, identification of omissions or redundant questions, and estimation of expected completion time. Feedback from the pilot suggested that EPs may not have been familiar with some of the names or terms included in the interventions listed even though they may actually be involved with implementing them. As a result, a short description of the EBI was included and a "not familiar" category was added so that the researchers could differentiate between EPs who do not use an intervention because they had not heard of it and those who are familiar with the intervention but have never used it.

\section{Procedure}

Once the project received ethical approval from the Manchester Institute of Education Research Integrity Committee and the research had been approved by NEPS in Ireland, a link to the questionnaire was emailed out to participants. The questionnaire was accessible and data were collected for 8 weeks. A follow up email was distributed 4 weeks into the study in the same way as the original email to encourage potential participants to complete the questionnaire.

When participants clicked on the link provided in the email, they were immediately presented with the participant information sheet prior to completing the questionnaire. Participants' consent was assumed by submitting the questionnaire.

\section{Analysis}

The quantitative data collected from the online questionnaire were analysed using SPSS version 22; the data were treated descriptively. The qualitative data from the questionnaire 
were analysed using conventional content analysis as described by Hsieh and Shannon (2005) using Nvivo software version 11 . First, the data were read repeatedly to gain immersion and a sense of the whole. Then the data that captured key thoughts or concepts were coded. Next, related codes were sorted into categories so that codes could be organised into meaningful clusters. Definitions were then given for each category, subcategory and code.

Inter-rater coding was undertaken in order to validate the coding scheme used for the content analysis. For this purpose $70 \%$ of the data from one qualitative question were independently coded by the lead author and a colleague researcher. An average number of codes generated by the researchers was identified. A percentage agreement of $84 \%$ was calculated by dividing the number of matched codes (66) by the average number of total codes (79). The researchers discussed the wording and semantics related to the generated codes to identify whether code-matching occurred. The lead author continued to code the remaining data independently.

\section{Results}

A total of 146 participants responded to the survey (127 females and 19 males) with 102 participants completing and submitting a completed survey. For an overview of participant roles see Table 1. As this study surveyed a range of EP practitioners, the following results and discussion apply to all those surveyed but the term 'EP' will be used to talk about these practitioners collectively.

[Table 1 near here]

\section{Sample Characteristics.}

As shown in table 1 the majority of participants were qualified EPs. Of the sample, $17(12 \%)$ considered themselves an ASD specialist meaning 125 (88\%) of the respondents did not have 
an ASD specialism. Table 2 shows the location of respondents with the majority being from English regions.

[Table 2 near here]

Table 3 shows the types of services in which the respondents were employed. The majority worked in an LA embedded Educational Psychology Service (EPS) and 63 (44.4\%) worked in a partially traded service. EPs employed in other ways included, working for a social enterprise, working as independent practitioners or being employed directly by a school. [Table 3 near here]

\section{Which evidence-based interventions are EPs likely to be involved with implementing?}

EPs in the UK and Ireland reported that on average (median), 30\% of their total caseload involved them implementing interventions for students with ASD although there was considerable variation in practice $(\mathrm{SD}=21.79)$.

The mean rating of the extent to which EPs were involved with implementing individual EBIs is shown in Table 4 in addition to the percentage of EPs in the sample who were unfamiliar with each intervention.

[Table 4 near here]

Across the sample, EPs most commonly used visual support, social narratives/stories, reinforcement, antecedent-based intervention, prompting, and social skills training. The least commonly used interventions were discrete trial teaching (DTT), exercise, pivotal response training (PRT), LEGO ${ }^{\circledR}$ Therapy, technology-aided instruction and intervention, extinction, 
time delay, and video modelling. The interventions EPs were least likely to be using were also those that EPs reported being least familiar with.

When asked to specify any other interventions that they were involved in implementing, EPs specified a range of models, approaches and programmes. The most frequently mentioned were Social Communication, Emotional Regulation and Transactional Support (SCERTS; Prizant, Wetherby, Rubin, Laurent, \& Rydell, 2005), Treatment and Education of Autistic and Communication related handicapped Children (TEACCH; Mesibov, Shea, \& Schopler, 2005), the National Autistic Society’s EarlyBird and EarlyBird Plus (Shields, 2001), and Attention Autism (Davies, 2013).

EPs in this study most commonly gained information about ASD interventions from their colleagues or the internet. They were also likely to gain this information from journal articles or reports.

\section{Which factors influence EPs' decision-making in relation to ASD interventions?}

The mean ratings of the extent to which EPs' judgements about interventions were influenced by each factor related to decision-making are shown in Table 5. On average, EPs reported that their decision-making was most frequently influenced by individual child needs and the school context. EPs identified 'other' factors which influenced their decisions to recommend interventions. These included teachers' views, school personnel's understanding of ASD, and the availability of EP time allocation.

[Table 5 near here]

Data about how these factors influenced EPs' decision-making in relation to recommending interventions were analysed using content analysis. Two broad areas were identified from the data: additional factors influencing EP decision-making and EPs' approach to intervention- 
planning. Data relating to additional factors were coded into simple categories as shown in Table 6. These factors were identified from two sources, an 'other' category in the closed question described above and an open ended question about decision making factors'. As EPs' approach to intervention-planning reflected a more complex and ongoing process, each category is summarised in Table 7 and some illustrative quotes are provided.

[Table 6 near here]

[Table 7 near here]

\section{Collaboration}

Collaboration was a main category in EPs' approach to intervention-planning. EPs reported that their approach to intervention-planning started with consultation and was conducted in collaboration with students, their parents and key adults. EPs took into account the perspectives of the student and sought to develop a shared understanding about why interventions may be used and develop agreed actions.

\section{Personalisation}

Personalisation was a main category in EPs' approach to intervention-planning. To ensure interventions were appropriate for individuals, EPs focused on students' individual characteristics and their strengths and weaknesses and experiences of being a student with ASD.

\section{Developing school capacity}

Developing school capacity was a small but important category in EPs' approach to intervention-planning. Working in collaboration with school personnel allowed for the exploration of their perceptions of an intervention in addition to developing a shared 
understanding of how and why an intervention will be used. EPs reported that they aimed to empower those who will be delivering the interventions by increasing their confidence in their ability to deliver them.

Assessment informed intervention.

Assessment informed intervention was a much smaller but still important category in EPs' approach to intervention-planning. EPs reported that they used the outcomes of triangulated assessment data, including "assess, plan, do, review" cycles and data gathered from school, parents and the students themselves to identify the priority needs for students which would inform the selection of interventions.

\section{Discussion}

This study surveyed EPs in the UK and Ireland in order to investigate the extent to which they are using evidence-based, focused interventions for students with ASD.

\section{Research question 1: To what extent are EPs in the UK and Ireland using focused EBIs for students with ASD?}

EPs in the UK and Ireland reported that on average, 30\% of their total caseload involved them in the implementation of interventions for students with ASD.

EPs reported that they were sometimes or often involved with delivering almost three quarters of the 31 identified EBIs. The EBIs which EPs used most often were visual supports, social stories, reinforcement, antecedent-based interventions, prompting, and social skills training. These interventions used most frequently by EPs tended to be interventions which can be implemented by the class teacher or classroom support assistants with little additional support and little need for technical training and as such can be easily integrated into the school day in mainstream settings (Bond, Symes, Hebron, Humphrey, Morewood, et al., 2016). Those interventions with which EPs are never or rarely involved with 
implementing included: DTT, exercise, PRT, LEGO ${ }^{\mathrm{TM}}$ therapy, technology-aided instruction and intervention, extinction, time delay, and video modelling. These interventions could be more difficult to implement in school-based settings as they may require a higher level of individual support from an adult who is highly trained (Rakos, 2006; Simpson, 2003) with more technical knowledge or resourcing. It may be the case that the EPs who responded to this survey may be more likely to encounter students with ASD who can manage in mainstream schools with more general as opposed to more specialised interventions. Additionally, those practices which use more behaviourist techniques such as operant conditioning have been found to be less favourable to parents (Callahan, Henson, \& Cowan, 2008) and so may be less likely to be implemented.

When asked to specify any other interventions that they are involved in implementing, EPs specified a range of models, approaches and programmes as opposed to focused interventions. One of these models, TEACCH (Mesibov et al., 2005), can be defined as evidence-based as it has been subject to efficacy trials and now has empirical support. Other approaches are defined as evidence-supported as they incorporate evidence-based strategies but the programmes themselves have not been subject to efficacy investigations (Wong et al., 2013); for example, SCERTS (Prizant et al., 2005) and DIR Floortime (Greenspan, Wieder, \& Hollander, 2007). EPs were also involved in delivering support programmes for parents and carers. Such programmes included Barnardo's Cygnet Programme and the National Autistic Society's EarlyBird Programmes. This demonstrates that in addition to focused interventions and comprehensive treatment models, EPs are also involved in the implementation of interventions which target the adults around children with ASD. It can be concluded from this research that EPs are involved with implementing focused interventions and comprehensive programmes which are evidence-based or evidence-supported. This is 
contrary to Stahmer, Collings, \& Palinkas (2005) who report that community practice of ASD interventionists generally rely on unsupported techniques.

\section{Research question 2: Which factors influence EPs' decision-making in relation to ASD interventions?}

The content analysis identified that EP's approach to intervention-planning covered four main areas: collaboration, assessment informed intervention, personalisation, and developing school capacity. Within these areas, EPs' decision-making in relation to interventions for students with ASD was influenced by a number of factors in addition to the interventions' evidence base. The most frequently cited factor was the individual needs of the student. EPs reported that they identified individual students' needs through the use of assessments. Another frequently cited factor was the views and perspectives of the students, their families and their teachers. These views were collected through consultation and were used to triangulate assessment data. The school context in which the intervention is to be implemented was another main factor influencing EPs' decision-making. EPs identified a number of contextual variables that would influence their decision-making and these included: the capacity of school personnel to deliver an intervention; the ability, skills and knowledge of school personnel; their level of training in specific interventions; and school personnel's perception of an intervention in addition to their motivation to deliver it.

The model of EBP supported by Spring et al. (2008) states that there are three overlapping elements involved in psychosocial intervention decision-making: best available evidence; client characteristics, values and preferences; and resources. This model also takes into consideration the environmental context. EPs' approach to intervention-planning and the factors they consider when making intervention decisions broadly align with this model (See Figure 1). While the model of EBP lends a good structure to describe EPs' approach to 
intervention-planning, not all of the findings of this study fit within this model. For example, the role of the EP in developing school capacity to deliver EBIs may be reflective of differences in the role of an EP in comparison to other professionals following EBP models.

[Figure 1 near here]

\section{Best available evidence.}

Best available evidence is thought to be found in systematic literature reviews, meta-analyses and randomised control trials (Frederickson, 2002). In relation to ASD interventions, there have been a number of systematic reviews of the intervention literature as a whole (e.g. Bond, Symes, Hebron, Humphrey, \& Morewood, 2016; Wong et al., 2013). Although EPs in this study reported that they obtained information about interventions from reports and peerreviewed journal articles, they were more likely to obtain this information from their colleagues or the internet.

\section{Client characteristics}

The best available evidence must be 'contextualised' by client characteristics (Spring et al., 2008) and professionals should use their expertise in considering an intervention alongside the child and family's, circumstances, preferences and values (Munro, 2011). EPs in this study assessed students' individual needs to inform intervention-planning and considered the perspectives of students, families and teachers to create shared outcomes.

\section{Resources}

When approaching intervention-planning, a judgement needs to be made about the resources currently available to deliver the intervention (Spring et al., 2008). EPs in this study most frequently mentioned financial resources, time allocation constraints and access to available, trained practitioners as factors which influence their intervention-planning. 


\section{Context}

Contextual factors are critical to the adoption of EBIs (Dingfelder \& Mandell, 2011) and variables at different contextual levels can interact to affect the ways in which interventions are implemented (Domitrovich et al., 2008). At the macro level, EPs' intervention-planning was influenced by school's financial position and their allocation of EP time. At the school level EPs intervention-planning was influenced by organisational factors such as resources and availability of trained professionals. At the individual level, EPs were influenced by staff perceptions of interventions and their motivation to deliver them.

\section{EBP in the $U K$ and Ireland.}

This survey has identified that, like their US counterparts (Sansosti \& Sansosti, 2013), EPs in the UK and Ireland are using many of those interventions which are considered to be evidence-based. As EPs in the UK and Ireland are not legally bound to implement EBIs in school settings, this allows EPs to consider a wide range of factors when planning interventions besides the interventions' evidence-base. This study demonstrates that while EPs are pragmatic in their approach to intervention-planning, their approach aligns well with models of EBP.

\section{Implications of this study for EP practice}

This study demonstrates that EPs are involved with using many of the interventions for students with ASD that are considered to be evidence-based. However, there are many interventions for ASD which EPs are not regularly involved with using, although it is unclear why this might be. An implication for EP practice is that in order to be offering students with ASD the best possible opportunities to meet individualised outcomes, EPs need to ensure they are familiar with EBI research for ASD through independent research or CPD in specific interventions. This study also has implications for the role of the EP and EPS in that they 
may be best placed to use research to support schools, through the development of frameworks, to support informed decision-making about selecting, implementing and evaluating interventions for individuals and groups of children with ASD (Magyar \& Pandolfi, 2012).

\section{Limitations of this study and future research}

This survey was completed with a relatively small, self-selecting sample of EP practitioners. Future research could be conducted with a larger sample of EPs which may enable further analysis into whether factors such as experience, training and specialisms have an effect on EPs' intervention practice.

Although this study identified those EBIs with which EPs were familiar and regularly involved with implementing, it was beyond the scope of this study to investigate why EPs were not frequently involved with implementing some of the EBIs identified by systematic reviews. Identifying why EPs are not involved with using some EBIs would be useful so that ways of overcoming barriers can be identified if needed.

This study used a content analysis approach to analysing the qualitative data from the survey and as a result, the findings regarding EPs approach to intervention-planning are preliminary. These findings, however, are a helpful starting point for further qualitative research into EPs' approach to intervention-planning for students with ASD. This study suggests that EPs' approach to intervention incorporates many of the elements of EBP. Follow up research including focus groups or in depth interviews would allow for a richer picture of EPs' approach to intervention-planning to be developed in addition to a model for professional EBP in relation to EPs' intervention practices. 


\section{Conclusion}

This study surveyed EPs' intervention practices for students with ASD. It was found that EPs are using many of the EBIs identified by recent systematic literature reviews; however, there are a quarter of EBIs that EPs are rarely using and a number with which EPs report being unfamiliar; further research to understand the reasons for this would be informative. In addition to the best available evidence for an intervention, EPs reported that there were other factors which influenced their decisions to recommend or implement an intervention. These factors were broadly consistent with models of EBP and included: individual students' needs, values and preferences; available resources; and school context. 


\section{References}

American Psychiatric Association. (2013). Diagnostic and statistical manual of mental disorders: DSM-5 (5th ed.). Washington, D.C.: American Psychiatric Association.

Bond, C., Symes, W., Hebron, J., Humphrey, N., \& Morewood, G. (2016). Educating Persons with Autistic Spectrum Disorder: A Systematic Literature Review. Trim: National Council for Special Education

Bond, C., Symes, W., Hebron, J., Humphrey, N., Morewood, G., \& Woods, K. (2016). Educational interventions for children with ASD: A systematic literature review 20082013. School Psychology International, 1-18. doi:10.1177/0143034316639638

Burnham, S. (2012). Realists or pragmatists? "Reliable evidence" and the role of the educational psychologist. Educational Psychology in Practice, 29, 19-35. doi:10.1080/02667363.2012.734277

Callahan, K., Henson, R. K., \& Cowan, A. K. (2008). Social validation of evidence-based practices in autism by parents, teachers, and administrators. Journal of Autism and Developmental Disorders, 38, 678-692. doi:10.1007/s10803-007-0434-9

Cohen, L., Manion, L., \& Morrison, K. (2013). Research Methods in Education (7th ed.). Hoboken: Taylor and Francis.

Davies, G. (2013). Attention Autism. Retrieved February 21, 2017, from http://ginadavies.co.uk/parents-services/professional-shop/

Department for Education. (2014). Special Educational Needs in England: January 2014. London.

Department for Education. (2016). Special Educational Needs in England: January 2016. London.

Department for Education (DfE). (2014). Special educational needs and disability code of 
practice : 0 to 25 years. London: DfE.

Dingfelder, H. E., \& Mandell, D. S. (2011). Bridging the research-to-practice gap in autism intervention: An application of diffusion of innovation theory. Journal of Autism \& Developmental Disorders, 41, 597-609. doi:10.1007/s10803-010-1081-0.Bridging

Domitrovich, C. E., Bradshaw, C. P., Poduska, J. M., Hoagwood, K., Buckley, J. a., Olin, S., ... Ialongo, N. S. (2008). Maximizing the implementation quality of evidence-based preventive interventions in schools: A conceptual framework. Advances in School Mental Health Promotion, 1, 6-28. doi:10.1080/1754730X.2008.9715730

Durlak, J. A., \& DuPre, E. P. (2008). Implementation matters: A review of research on the influence of implementation on program outcomes and the factors affecting implementation. American Journal of Community Psychology, 41, 327-350. doi:10.1007/s10464-008-9165-0

Frederickson, N. (2002). Evidence-based practice and educational psychology. Educational and Child Psychology, 19, 96-111.

Goldacre, B. (2013). Building evidence into education.

Greenspan, S. I., Wieder, S., \& Hollander, E. (2007). The developmental individualdifference, relationship-based (DIR/Floortime) model approach to autism spectrum disorders. In E. Hollander \& E. Anagnostou (Eds.), Clinical Manual for The Treatment of Autism.

Hsieh, H.-F., \& Shannon, S. E. (2005). Three approaches to qualitative content analysis. Qualitative Health Research, 15, 1277-1288. doi:10.1177/1049732305276687

IDEA. Individuals with Disabilities Education Improvement Act (2004).

Magyar, C. I., \& Pandolfi, V. (2012). Considerations for establishing a multi-tiered problemsolving model for students with autism spectrum disorders and comorbid emotionalbehavioral disorders. Psychology in the Schools, 49, 975-987. doi:10.1002/pits.21645 
Mesibov, G. B., Shea, V., \& Schopler, E. (2005). The TEACCH approach to autism spectrum disorders. Springer Science \& Business Media. doi:10.1007/978-0-306-48647-0

Miller, A., \& Frederickson, N. (2006). Generalizable findings and idiographic problems: Struggles and successes for educational psychologists as scientist-practitioners. In D. A. Lane \& S. Corrie (Eds.), The Modern Scientist-Practitioner: A Guide to Practice in Psychology. Routledge.

Munro, E. (2011). The Munro Review of Child Protection: Final Report - A Child-Centred System: A Review and Commentary. The munro review of child protection: Final report a child-centred system. https://doi.org/10.1375/jcas.36.3.164

National Autism Center. (2009). National Standards Project. https://doi.org/10.1097/00006199-197003000-00021

National Institute for Health and Clinical Excellence. (2011). Autism diagnosis in children and young people: Recognition, referral and diagnosis of children and young people on the autism spectrum.

Prizant, B. M., Wetherby, A. M., Rubin, E., Laurent, A. C., \& Rydell, P. J. (2005). The SCERTS[TM] Model: A Comprehensive Educational Approach for Children with Autism Spectrum Disorders. Brookes Publishing Company.

Rakos, R. F. (2006). Applied behavior analysis: Niche therapy par excellance. Behavior and Social Issues, 15, 185-191.

Sackett, D., Rosenberg, W. M. C., Gray, J. a., Haynes, R. B., \& Richardson, W. S. (1996). Evidence based medicine: What it is and what it is not. British Medical Journal, 312, 71-72. doi:10.1136/bmj.312.7023.71

Sansosti, F. J., \& Sansosti, J. M. (2013). Effective school-based service delivery for students with autism spectrum disorders: Where we are and where we need to go. Psychology in the Schools, 50, 229-224. doi:10.1002/pits 
Shields, J. (2001). The NAS EarlyBird Programme. Autism, 5, 49-56. doi:10.1177/1362361301005001005

Simpson, R. L. (2003). Policy-related research issues and perspectives. Focus on Autism and Other Developmental Disabilities, 18, 192-196. doi:10.1177/10883576030180030701

Spring, B., \& Hitchcock, K. (2010). Evidence-based practice. Corsini Encyclopedia of Psychology. doi:10.1002/9780470479216.corpsy0330

Spring, B., Walker, B., Brownson, R., Mullen, E., Newhouse, R., Satterfield, J., \& Hitchcock, K. (2008). Definition and Competencies for Evidence-Based Behavioral Practice ( $E B B P$ ). Evanston, IL.

Stahmer, A. C., Collings, N. M., \& Palinkas, L. A. (2005). Early intervention practices for children with autism: Descriptions from community providers. Focus on Autism and Other Developmental Disabilities, 20, 66-79. doi:10.1097/OPX.0b013e3182540562.The Waite, V., \& Woods, K. (1999). Educational psychologists' assessments of autism.

Educational Psychology in Practice, 15, 167-173. doi:10.1080/0266736990150303

Wong, C., Odom, S. L., Hume, K., Cox, A. W., Fettig, A., Kucharczyk, S., ... Schultz, T. R. (2013). Evidence-Based Practices for Children, Youth, and Young Adults with Autism Spectrum Disorder. https://doi.org/DOI 10.1007/s10803-014-2351-z 